* Doutoranda em Direito Público pela PUC/RS. Mestre em Direito Tributário pela UFRGS-RS. Professora da Pós-Graduação em Direito e Gestão Tributária da UNISINOS. Pós-Graduada em Direito Empresarial pela Fundação Getúlio Vargas. Mestre em Direito Tributário pela UFRGS. Membro do Conselho de Pareceristas da Revista de Finanças Públicas, Tributação e Desenvolvimento, da Revista Quaestio Juris e da Revista de Direito da Cidade. Advogada.
EXTRAFISCALIDADE E INCENTIVOS

À INOVAÇÃO TECNOLÓGICA

EXTRAFISCALITY AND INCENTIVES

FOR TECHNOLOGICAL INNOVATIONS

\section{Larissa Rodrigues Laks*}

Como citar: LAKS, Larissa Rodrigues. Extrafiscalidade e incentivos à inovação tecnológica. Revista do Direito Público, Londrina, v. 11, n. 2, p.230-259, ago. 2016. DOI: $10.5433 / 1980-511 X .2016 v 11 \mathrm{n} 2 \mathrm{p} 230$. ISSN: 1980-511X.

RESUMO: O presente artigo procura refletir sobre as bases teóricas da extrafiscalidade e sua aplicação no incentivo à inovação tecnológica, mostrando como evoluiu na última década a legislação brasileira no que se refere ao estímulo, por meio de renúncia de impostos, às atividades de pesquisa e desenvolvimento (P\&D). Em particular, analisa-se o caso da Lei do Bem (Lei 11.196/2005) e constata-se que, apesar do incremento no número de empresas que passaram a acessar o programa de incentivos fiscais, sua abrangência ainda é limitada, e que as empresas brasileiras ainda investem pouco em pesquisa e desenvolvimento, o que pode ser atribuído ao risco que o negócio representa, à cultura conservadora, à burocracia interna, além da insegurança jurídica em torno do marco regulatório. 
Palavras-chave: Extrafiscalidade, incentivos fiscais, inovação, pesquisa e desenvolvimento (P\&D).

ABSTRACT: This paper discusses the theoretical foundations of extrafiscality; its application in encouraging technological innovation, which demonstrates how Brazilian law has evolved over the past decade; and relates it to the stimulus, tax waivers and the researching and development of activities (R\&D). Specifically, this paper will analyze the Good Law (Law 11.196 / 2005) and its limited scope - despite the increase in the number of companies that have access to the tax incentive program. However, Brazilian companies still invest little in research and development activities, which can be attributed to the risk or cost of business and what it represents in conservative culture, in internal bureaucracy, and beyond the legal uncertainty of the regulatory framework.

Key words: Extrafiscality, tax incentives, innovation, Research and Development (R\&D). 


\section{INTRODUÇÃO}

O tipo de Estado de Bem-Estar Social sobre o qual se assentam boa parte das sociedades desenvolvidas e que influenciou a Constituição brasileira de 1988, aos ventos da redemocratização, se construiu a partir de um diagnóstico de que as forças do mercado, por si só, não seriam capazes de instaurar a prosperidade da nação, do que decorreria a necessidade de intervenção do Estado, tanto na atividade econômica quanto na construção de uma rede de proteção social.

Do ponto de vista do Direito Financeiro e Tributário, isso se materializou através de duas vias: a primeira, pelo gasto público direto, seja em benefícios sociais ou investimentos, e a segunda, por meio do que denomina-se extrafiscalidade, ou seja, o recurso à função ordenatória, interventiva ou redistributiva da imposição tributária visando objetivos mais amplos do que a mera obtenção de receitas, como a promoção dos direitos fundamentais e do desenvolvimento social e econômico.

A extrafiscalidade representa, portanto, um método utilizado pelo Estado Social e Democrático de Direito do século XX, que tem por objetivo estimular ou desincentivar determinadas condutas para os fins de concretização das políticas públicas eleitas como prioritárias na Constituição Federal. Embora a extrafiscalidade possa se manifestar na imposição de tributos voltados a desincentivar determinados comportamentos, principalmente na área ambiental, ou com fins regulatórios, como os impostos de importação e exportação, entre tantos outros, que também geram receitas, é na seara dos incentivos fiscais e das renúncias de receitas com propósito de estimular o desenvolvimento socioeconômico, em todas as suas dimensões, que se insere a maior parte dos dispositivos extrafiscais. E é também nesse contexto que se 
insere o presente estudo, ao focalizar os incentivos ao desenvolvimento tecnológico e científico.

A base para tais incentivos, como será visto, foi assentada na Constituição de 1988, ao estabelecer nos seus artigos 218 que "o Estado promoverá e incentivará o desenvolvimento científico, a pesquisa, a capacitação científica e tecnológica e a inovação”. Com base nesse mandamento constitucional, produziram-se desde os anos 90 diversas legislações com o intuito de estimular, por meio de incentivos fiscais, o desenvolvimento tecnológico e científico, começando pela Lei de Informática, em 1991, até a Lei do Bem, em 2005.

Do ponto de vista jurídico, a Lei do Bem é a mais completa legislação já produzida no país com o intuito de estimular os investimentos em pesquisa e inovação, mas, conforme será demonstrado, seus resultados são ainda bastante limitados. Não só o volume de receitas efetivamente renunciado com o programa é pouco expressivo, em comparação, por exemplo, à Lei de Informática, como o incremento no dispêndio privado em P\&D, por influência desses incentivos, é pouco expressivo.

Nesse contexto, contudo, parece haver um descompasso entre os finalidades pretendidos através da implementação da política fiscal e as suas consequências, sendo necessário identificar os múltiplos fatores que, no domínio do Direito Tributário ou de outras ciências, como a Economia, poderiam estar reduzindo a efetividade dessa norma tributária. Considerando o papel que o desenvolvimento tecnológico tende a representar em relação ao desenvolvimento social e econômico no contexto atual das nações, o artigo também busca abordar a necessidade de maior divulgação ou estímulo à utilização dos benefícios fiscais previstos nas normas extrafiscais existentes, para incremento dos seus resultados. 


\section{O CONCEITO JURÍDICO E O DESENVOLVIMENTO ECONÔMICO DA TRIBUTAÇÃO EXTRAFISCAL}

Os limites que dão contorno ao Direito Tributário, conforme Correia Neto (2014, p. 75-76), tendem a apartar o tributo das demais instituições que compõe o quadro teórico e jurídico das finanças públicas e afastá-lo das preocupações relativas à sua finalidade e eficácia. Numa interpretação mais restrita do Direito Tributário, portanto, poder-se-ia dizer que a análise jurídica dos incentivos fiscais e renúncias que se expressam através da tributação extrafiscal transcenderia os estritos limites da relação impositiva e do tributo enquanto instrumento de mera arrecadação.

$\mathrm{O}$ autor argumenta, ainda, que existiria certa ambiguidade no adjetivo "extrafiscal", na medida em que o prefixo "extra" sugere a inclusão, no debate tributário, de elementos que dele, em princípio, não fariam parte, pois lhe seriam estranhos. Além disso, refere que o conceito expresso pelo prefixo "extra", que transcenderia o âmbito do conceito fiscal propriamente dito, deixaria subentendida a ideia de que a tributação devesse ser, em alguma medida, neutra, de forma a não almejar fins que transcendessem aqueles restritos à mera arrecadação de recursos ao erário.

$\mathrm{O}$ conceito de neutralidade tributária, portanto, estaria relacionado a uma visão segundo a qual o tributo não deve interferir, tanto quanto possível, no processo de trocas econômicas, nem gerar distorções (CALIENDO, 2009b, p. 113). Trata-se, contudo, de um objetivo ideal, uma vez que todo tributo influi de alguma forma sobre o processo econômico e sobre as decisões dos agentes econômicos.

Portanto, é possível que o princípio da neutralidade em matéria 
tributária seja relativizado, de forma a ser caracterizado como um limite ou orientação ao legislador, no sentido de conceber medidas tributárias que busquem interferir o mínimo possível no equilíbrio econômico, para evitar a produção de reações artificiais (BARBOSA, 2008, p. 265-269). Ao mesmo tempo, contudo, haveriam situações em que o ambiente econômico em si não garantiria a aludida neutralidade, de modo que se façam necessárias medidas excepcionais para que ela seja de fato implementada. Nesse contexto, a "neutralidade fiscal omissa", caracterizada pela omissão de intervenção fiscal nas situações em que isso se fizesse necessário, em função da existência de distorções decorrentes da realidade de fato, na prática seria prejudicial.

Assim, seja para corrigir falhas de mercado, como as que tornam o ambiente econômico não neutro, seja para perseguir outros objetivos sociais, econômicos e políticos, surge a faceta extrafiscal do tributo. Uma faceta que, no âmbito das políticas públicas, adquire uma conotação orientada a induzir condutas e produzir efeitos que se considerem importantes para o desenvolvimento socioeconômico, ambiental, tecnológico ou de outra natureza eleita como importante pelo sistema jurídico.

Por outro lado, é interessante notar que, embora a denominação "extrafiscalidade" seja propositalmente conceituada de forma a designar finalidades que não sejam as meramente fiscais ou arrecadatórias, não existe entidade tributária pura, ou seja, não existem tributos com funções exclusivamente fiscais ou extrafiscais (CARVALHO, 2007). Isso porque os tributos também cumpririam funções arrecadatórias, e, da mesma forma, os tributos com finalidade fiscal declarada possuiriam efeitos externos e repercutiriam, em algum grau, nas escolhas dos agentes econômicos, o que Nabais (2003, p. 113) define como extrafiscalidade 
imprópria ou imanente.

A diferenciação principal entre a fiscalidade e a extrafiscalidade residiria, portanto, no fato de que esta busca lidar conscientemente com os efeitos sociais (ou externos) da tributação, permitindo ao pensamento jurídico "dar-se conta da problemática dos fins e efeitos dos tributos e articular questionamentos dessa ordem no interior do direito positivo" (CORREIA NETO, 2014, p. 91). Numa visão mais restritiva, portanto, estariam afastados da noção de extrafiscalidade quaisquer efeitos que não sejam rigorosamente premeditados pelo legislador, como os efeitos secundários de um imposto com fins fiscais concebido para outros fins.

Nas definições doutrinárias mais recentes, entretanto, esse imperativo tenderia a ser relativizado, assim como a distinção entre o que é e o que não é extrafiscalidade, pelo menos nos termos supramencionados, na medida em que todos tributos apresentariam, em maior ou menor grau, características extrafiscais. Assim, a distinção entre os conceitos de fiscalidade e extrafiscalidade seria predominantemente decorrente da intensidade com que são perseguidos fins fiscais ou extrafiscais, e não da qualidade, baseando-se primordialmente na finalidade e nos objetivos de cada tributo, não considerando somente os seus efeitos. Nesse contexto, pertinentes as palavras de Correia Neto (2014, p. 94), quando refere que: "Dizer que todos os tributos podem produzir outros efeitos, além da obtenção de recursos públicos, não é o mesmo que defender que todos eles sejam endereçados a tal propósito.”

Dessa forma, sintetizando as múltiplas dimensões da extrafiscalidade, destacam-se três níveis em que o fenômeno extrafiscal se manifesta (CORREIA NETO, 2014, p. 96). Em primeiro lugar, na definição de objetivos e fundamentos não financeiros que justifiquem a utilização de certos tributos ou a conformação diferenciada de sua 
regra-matriz ou seu regime jurídico. Em segundo lugar, na imposição de derrogações em relação ao regime padrão aplicável à generalidade dos tributos de mesma espécie, o que pode ocorrer tanto em nível constitucional de estabelecimento de competências ou imunidades tributárias, quanto no plano legislativo infra-constitucional. Em terceiro e último lugar, há os efeitos externos - sociais, econômicos, ambientais - diversos da geração de receitas, que podem ser produzidos pela norma tributária.

Portanto, a compreensão do terreno no qual o Direito Tributário atua no que se refere aos incentivos às inovações tecnológicas requer, antes de mais nada, uma digressão sobre os fundamentos econômicos da extrafiscalidade, e de como tais fundamentos foram se alterando e modernizando através dos tempos.

É importante referir, ainda, que a tributação extrafiscal, baseado no pressuposto econômico fundamental de que as pessoas respondem aos incentivos que lhes são outorgados, envolvendo a aceitação de algum nível de falha de mercado e de necessidade de intervenção estatal, é um conceito que foi negado pela teoria econômica dominante até o século XIX, o liberalismo clássico. ${ }^{1}$ Por isso, os tributos tinham função estritamente arrecadatória nessa época, sendo limitados os casos em que os mesmos eram utilizados para fins extrafiscais.

Esta também era a visão da chamada escola neoclássica ${ }^{2}$ de economia, que surge no fim do século XIX, unindo os ideais do

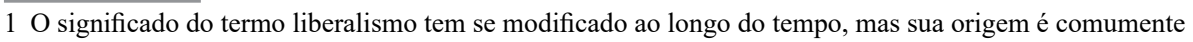
atribuída ao filósofo inglês John Locke, no século XVII, em contraposição ao Estado absolutista. Os economistas liberais clássicos, como Adam Smith, defendiam uma atuação minimalista do Estado, via de regra restrita a garantir a justiça e os direitos dos cidadãos, preservar a propriedade e a ordem pública. Vide SMITH, Adam. Riqueza das Nações. Tradução Norberto de Paula Lima, $1^{\text {a }}$ edição. São Paulo: Folha de S.Paulo, 2010, passim.

2 Termo utilizado pela primeira vez por VERBEN, Thorstein. The Preconceptions of Economic Science - III. The Quarterly Journal of Economics. Vol. 14, No. 2 (Fev., 1990), pp. 240-269. 
liberalismo clássico a uma nova forma de analisar as decisões econômicas a partir de cálculos matemáticos de maximização de funções de utilidade - a chamada abordagem marginalista, aplicada por Stanley Jevons e León Walras, na construção de uma teoria subjetiva do valor em contraposição à teoria do valor do trabalho desenvolvida pelos clássicos (BRESSER PEREIRA, 1968). Tanto para os liberais clássicos, quanto neoclássicos, o mercado teria a capacidade de se autorregular e gerar uma dinâmica de crescimento econômico tanto mais equilibrado e eficiente quanto menores fossem as interferências do governo. Nesses termos, a atuação do governo deveria ser o mais neutra possível, do ponto de vista tributário, fiscal ou monetário.

Contudo, a partir da I Guerra Mundial e da Grande Crise de 1929, a utilização do tributo como instrumento de redistribuição de renda e de indução econômica se desenvolve e se consolida, sob influência de uma profunda revisão no pensamento econômico dominante. Nesse contexto, o célebre economista inglês John Maynard Keynes sustentava que, ao contrário do predito pela teoria neoclássica, a economia capitalista não tenderia naturalmente ao equilíbrio e ao pleno emprego e que, devido à incerteza e volatilidade que caracterizavam o investimento privado, seria fundamental a atuação do Estado sobre a economia, principalmente por meio de sua política de impostos e gastos, para sustentar a demanda efetiva e impedir as crises (KEYNES, 1936, p. 347).

Essa concepção inovadora para a época influenciou as políticas de combate à recessão implementadas a partir de 1933 pelo presidente americano Franklin Roosevelt e, nas décadas seguintes, as políticas econômicas de todas as grandes nações capitalistas, incluindo aquelas que implementaram o chamado Estado de Bem-Estar Social (BALEEIRO, 2006, p. 812). Tanto o gasto público, quanto os tributos, deveriam 
ser utilizados de modo ativo para tentar garantir o equilíbrio social e econômico que o mercado, por sua "mão invisível” (SMITH, 2010, p. 177), mostrou-se incapaz de assegurar.

Dessa forma, pode-se dizer que o conceito de extrafiscalidade foi desenvolvido de forma associada ao do Estado Social e Democrático de Direito, que pressupunha algum grau de intervenção governamental na atividade econômica e social (SARLET, 2001), de modo a proteger os direitos individuais, reduzir as desigualdades sociais e estimular o desenvolvimento econômico (CALIENDO, 2009a, p. 179-181).

Esse modelo de Estado interventor começou a ser profundamente questionado na década de 70 , diante da situação de estagnação das economias desenvolvidas, quando uma nova geração de economistas neoclássicos promoveram uma espécie de contrarrevolução no pensamento econômico dominante, criticando a eficiência e a própria consistência científica das políticas fiscais keynesianas de gasto ou incentivo fiscal, por exemplo JARDIM; LICHANDLL; GALA (2009). Do ponto de vista teórico, essa geração de economistas, também chamada novo clássica, por fazer uma atualização da teoria neoclássica (FERRARI FILHO, 1991), pautam sua análise por fundamentos microeconômicos, que são modelos que tentam explicar fenômenos econômicos agregados a partir do comportamento de indivíduos racionais e, embora advoguem em geral políticas de desregulamentação dos mercados, reconhecem a existência de falhas de mercado e outras situações em que se pode justificar a intervenção estatal (MANKIW, 2009).

É o caso do conceito de externalidades desenvolvido por Cecil Pigou, ao tratar dos efeitos de uma decisão sobre aqueles que não participaram dela (CALIENDO, 2013, p.176-179.). Eles são negativos, quando a ação de um agente econômico cria custos para os demais 
(poluição atmosférica ou congestionamento, por exemplo) e positivos quando geram benefícios (investimentos governamentais e privados em infraestrutura e inovação tecnológica, por exemplo). Um bom exemplo de externalidade negativa seria caracterizado pela poluição ambiental, por exemplo, constituindo-se como bom exemplo de externalidade positiva as situações de transbordamento tecnológico de uma empresa para outra (MANKIW, 2009, p. 10 e 207).

Ao reconhecer a existência de externalidades, a teoria neoclássica flexibiliza a visão liberal clássica, caracterizada pela rejeição à intervenção estatal, e aceita que o Estado intervenha pontualmente, para corrigir falhas de mercado ou induzir ações que o sistema de preços não é capaz de garantir por si só. Ou seja, mesmo reconhecendo que o Estado deve se afastar ao máximo da atividade econômica, justifica-se e confere-se relevância para a extrafiscalidade, como instrumento de intervenção seletiva e não generalizada.

Os incentivos tributários à inovação, entretanto, são justificados não apenas à luz da teoria das externalidades, mas principalmente à luz de uma outra importante teoria econômica formulada no século XX pelo economista austríaco Joseph Schumpeter. Trata-se de uma teoria que confere papel central à inovação no processo de desenvolvimento capitalista, e que difere radicalmente da teoria neoclássica, na qual as firmas são vistas como meros agentes maximizadores de lucros.

Em resumo, segundo Schumpeter (1939), o capitalismo se desenvolvia em razão de sempre estimular o surgimento dos empreendedores, ou seja, de capitalistas ou inventores extremamente criativos, que seriam os responsáveis por todas as ondas de prosperidade que o sistema conhecia. Conforme Voltaire Schilling: 
Para Schumpeter eram eles os heróis da modernidade. O progresso dependia essencialmente desta vanguarda audaz e inventiva, que quase sempre surgia em grupos (Henry Ford, por exemplo, era ligado a Thomas Alva Edison)[...]. No entender de Schumpeter, toda a inovação implica pois numa "destruição criadora". O novo não nasce do velho, mas sim brota ao seu lado e supera-o. Pode-se derramar lágrimas pelos que foram massacrados pela expansão da tecnologia mais recente, mas isto não detém o progresso nem altera o seu resultado final.(SCHILLING, 2008, p. 1).

A concepção de Schumpeter sobre o desenvolvimento econômico envolve, portanto, não só uma visão diferente de firma - locus de atuação do empresário inovador e de desenvolvimento da inovação e da teoria da produção, como uma visão diferente do próprio processo evolutivo. A instabilidade e o desequilíbrio, fruto do processo de inovação e da "destruição criadora" (SCHUMPETER, 1961, p. 108), deixam de se tornar um problema em si para tornar-se fonte do crescimento e do desenvolvimento.

É importante destacar o pensamento de Schumpeter porque boa parte das políticas de inovação adotadas no Brasil no período recente têm inspiração no que denomina-se neo-shumpeterianismo, escola que vê na concorrência um processo evolutivo e dinâmico em que surgem as inovações. Segundo esta abordagem, entretanto, as inovações somente são viáveis se a interação entre as estruturas sociais e institucionais (com os apropriados incentivos à pesquisa) for bem definida dentro do conceito de força impulsionadora da economia (HADDAD, 2010, p. 31-32). 
Nesse contexto, a inovação é resultado de um amplo espectro de fatores, não puramente econômicos, mas também institucionais e sociais, sobre o qual o Direito exerce um papel fundamental. Daí a suma importância de políticas tributárias extrafiscais com foco na indução de inovações.

\section{A EXTRAFISCALIDADE E OS INCENTIVOS À CIÊNCIA E TECNOLOGIA NO BRASIL}

No Brasil, o conceito de extra-fiscalidade aparece pela primeira vez na Constituição Federal em 1988, que representou a instituição do Estado Social e Democrático de Direito no país e que, por essa razão, não poderia deixar de consolidar, no seu texto, dispositivos representativos do papel do Estado e de sua ação positiva como fomentador do desenvolvimento econômico e social, da ordem econômica fundada na valorização do trabalho e na livre iniciativa, que tem por fim assegurar a todos existência digna, conforme os ditames da justiça social (art. 170 da CF). Ainda, segundo o artigo 174, $\S 1^{\circ}$, o Estado deve normatizar, regular e planejar a atividade econômica, de forma determinante para o setor público, e indicativa, para o setor privado.

Art.174: Como agente normativo e regulador da atividade econômica, o estado exercerá, na forma da lei, as funções de fiscalização, incentivo e planejamento, sendo este determinante para o setor público e indicativo para o setor privado. $\S 1^{\circ}$ - A lei estabelecerá as diretrizes e bases do planejamento do desenvolvimento nacional equilibrado, o qual incorporará e compatibilizará os planos nacionais e regionais 
de desenvolvimento. (BRASIL, 1988, p. 81).

Tal intervenção do Estado na economia, prevista no dispositivo supratranscrito, deve, contudo, ser regulamentada e obedecer a certos limites, como se observa, por exemplo, no art. $165, \S 6^{\circ}$, no que pertine às práticas de políticas extrafiscais e à criação de fórmulas de controle em relação à intervenção estatal pela via dos incentivos e benefícios fiscais, conforme determina o art. $165, \S 6^{\circ}$ do mesmo dispositivo, ao referir que:

O projeto de lei orçamentária será acompanhado de demonstrativo regionalizado do efeito, sobre as receitas e despesas, decorrentes de isenções, anistias, remissões, subsídios e benefícios de natureza financeira, tributária e creditícia. (BRASIL, 1988, p. 75).

Portanto, a intervenção do Estado na economia deve almejar uma espécie de regulação analítica, que leve em conta custos e benefícios (SUSTEIN, 2014, p.166), sendo no presente estudo, segundo tais conceitos, conferida especial atenção para as fórmulas interventivas que visem fomentar o desenvolvimento econômico, científico e tecnológico. Interessante referir, ainda, que o mercado de tecnologia e inovação requer altos investimentos, em relação ao que há um certo consenso, no sentido de que os riscos de tais investimentos devam ser suportados também pelo governo, e divididos com a sociedade, pela via das renúncias de receitas representadas pelos incentivos fiscais.

Por esta razão, a Constituição de 1988 também dedica um capítulo separado para a ciência, tecnologia e inovação (capítulo IV), prevendo em seus artigos 218 (especialmente o parágrafo 4) e 219 que: 
Art. 218. O Estado promoverá e incentivará o desenvolvimento científico, a pesquisa, a capacitação científica e tecnológica e a inovação. $\S 1^{\circ}$ A pesquisa científica básica e tecnológica receberá tratamento prioritário do Estado, tendo em vista o bem público e o progresso da ciência, tecnologia e inovação (...).

$\S 4^{\circ}$ A lei apoiará e estimulará as empresas que invistam em pesquisa, criação de tecnologia adequada ao País, formação e aperfeiçoamento de seus recursos humanos e que pratiquem sistemas de remuneração que assegurem ao empregado, desvinculada do salário, participação nos ganhos econômicos resultantes da produtividade de seu trabalho (...).

Art. 219. O mercado interno integra o patrimônio nacional e será incentivado de modo a viabilizar o desenvolvimento cultural e sócio-econômico, o bem-estar da população e a autonomia tecnológica do País, nos termos de lei federal. (BRASIL, 1988, p. 96).

Nesse contexto, observa-se que, a partir das previsões existentes na Constituição de 1988, relativamente à necessidade de atuação estatal para o fomento do desenvolvimento econômico e da inovação, as preocupações dos governos brasileiros passam a se desenvolver no sentido de necessariamente relacionar o desenvolvimento econômico ao tecnológico (CALIENDO, 2012, p. 148). Por via oblíqua, constatou-se a necessidade de redução da carga tributária, como forma de estímulo ao desenvolvimento da inovação e da tecnologia, políticas estas que começaram a se incrementar a partir dos anos 90, ganhando maior expressão na última década. 
Segundo tais objetivos, diversas leis foram editadas, tais como a Lei 8.248, de 23/10/1991, que dispõe, entre outros pontos, sobre incentivos fiscais para atividades de pesquisa no setor de informática, além da Lei 8.661/1993, que regulava o chamado Programa de Desenvolvimento Tecnológico e Industrial - PDTI, e oferecia diversos incentivos fiscais, como a possibilidade de reduzir o imposto de renda devido em até um oitavo e a isenção de IPI na aquisição de equipamentos, máquinas e instrumentos utilizados na pesquisa e no desenvolvimento tecnológico.

$\mathrm{Na}$ década passada, outras leis foram editadas, na busca pela maior concretização da participação governamental, via estímulos fiscais e de outras naturezas, no desenvolvimento tecnológico. A Lei 10.973/2004, também conhecida como “Lei da Inovação", por exemplo, assentou as bases para a criação de um ambiente de cooperação para inovação entre o setor privado e as instituições públicas dedicadas à pesquisa básica e aplicada de caráter científico e tecnológico (capítulos II e III), além de prever duas formas distintas de estímulo direto ao desenvolvimento de produtos e processos inovadores em empresas nacionais: concessão de recursos financeiros, sob a forma de subvenção econômica, financiamento ou participação societária (art. 19, $\S 2^{\circ}$ ), sujeita à aprovação prévia de projeto; e concessão de incentivos fiscais (art. 28), sujeita à futura regulamentação, o que foi feito posteriormente pela Lei $n^{\circ} 11.196 / 2005$, a chamada "Lei do Bem".

Na prática, a Lei do Bem substituiu a lei do PDTI, instituindo não só um novo regime de incentivo fiscal para a inovação tecnológica, mas também uma série de outros regimes fiscais especiais, como o da plataforma de exportação de serviços de tecnologia da informação (REPES) e o de aquisição de bens de capital para empresas exportadoras (RECAP). Os incentivos à inovação fazem parte do capítulo III da Lei 
do Bem e preveem desde deduções ampliadas dos gastos com P\&D da base de cálculo dos tributos sobre o lucro até a depreciação acelerada - e integral, a partir de 2008 - das aquisições de máquinas, equipamentos e instrumentos utilizados em atividades de pesquisa e desenvolvimento de inovações, além de manter a redução de $50 \%$ no IPI incidente sobre essas mesmas aquisições, benefício este já previsto na Lei 8.661/1993. $\mathrm{O}$ art. 21 da Lei do Bem também prevê que a União, por intermédio das agências de fomento de ciências e tecnologia, possa subvencionar o valor da remuneração de pesquisadores, titulados como mestres ou doutores, empregados em atividades de inovação tecnológica em empresas localizadas no território brasileiro.

Destaque-se que um dos principais atrativos da Lei do Bem diz respeito à facilidade de acesso e implementação dos incentivos fiscais à inovação, os quais não dependem de prévia autorização governamental. Contudo, é importante referir que as empresas beneficiárias devem anualmente prestar informações sobre suas atividades de P\&D, e que a adequação da forma de aplicação dos benefícios fiscais podem ser fiscalizados a qualquer tempo pela Receita Federal do Brasil, conforme permissivo contido no art.24 Lei 11.196/2005. Além disso, para ter direito aos benefícios, a empresa deve ser necessariamente optante pela sistemática de tributação segundo o lucro real, estar em situação de regularidade fiscal e ter lucro no exercício, pois o período de possível aplicação dos benefícios decorrentes da lei é apurado e aplicável a cada ano fiscal (CALOZAIO, 2011, p.102).

A necessidade de tributação segundo o lucro real, para a possibilidade de usufruto dos benefícios fiscais em vigor, pode ser criticada como uma forma de restrição dos benefícios apenas às grandes empresas, optantes por este regime de tributação, excluindo a possibilidade de sua 
extensão às empresas médias e pequenas, tributadas segundo o regime do lucro presumido ou pelo regime do Simples. Contudo, conforme se observa, na prática, faz-se necessária a tributação pelo lucro real, pois os benefícios são variáveis e sujeitos precisamente à comprovação de despesas dedutíveis da base de cálculo do Imposto de Renda de Pessoa Jurídica (IRPJ) e da Contribuição Social sobre Lucro Líquido (CSLL).

Se a empresa é optante pela tributação com base no lucro presumido ou no Simples, não são consideradas as despesas efetivamente incorridas para apurar a base de cálculo do IRPJ e da CSLL, mas utilizadas margens presumidas de dedução diferenciadas por setor econômico apenas, independentemente das reais despesas incorridas. Dessa forma, tal regime de tributação é incompatível com a concessão de benefícios proporcionais aos gastos e investimentos efetivamente realizados pelas empresas, os quais não poderiam ser calculados nem aferidos segundo gastos presumidos ou estimativos, o que permitiria desvios ao objetivo da lei, sendo o estímulo claramente projetado para os gastos efetivamente realizados, como ocorre na tributação pelo lucro real.

Sendo assim, os principais benefícios fiscais implementados pela Lei do Bem, incluindo as modificações legais realizadas nos anos recentes, dizem respeito à:

- os gastos correntes em atividades de P\&D podem ser deduzidos da base de cálculo do IRPJ e da CSLL à taxa de 160\% (ou seja, 1,6 vezes o valor efetivamente gasto, quando o normal seria de apenas $100 \%$ ) ou $180 \%$ em caso de aumento do número de pesquisadores contratados superior a $5 \%$;

- 2) os investimentos em máquinas e equipamentos destinados à inovação podem ser depreciados 
integralmente no ano de aquisição para fins do IRPJ e da CSLL;

- 3) a aquisição de ativos intangíveis relacionados a atividades tecnológicas podem ser totalmente amortizados no ano de compra para fins de cálculo do IRPJ;

- 4) o Imposto sobre Produtos Industrializados (IPI) para bens de capital destinados à inovação pode ser reduzido em 50\%;

- 5) crédito tributário de IRPJ de 10\% nas remessas internacionais referentes a royalties e assistência técnica para gastos realizados a partir de 2009;

- 6) eliminação de impostos incidentes sobre remessas internacionais referentes a registros de patentes e marcas; e

- 7) subvenção de $40 \%$ da folha de pagamento dos pesquisadores com dedicação integral (ou 60\% se empresa for localizadas nas regiões Norte e Nordeste).

Diversos estudos, entre eles Araújo (2010) e Memória (2014), tem convergido em reconhecer a importância dos incentivos fiscais para o desenvolvimento de P\&D no Brasil, mas constatam que ainda são poucas as empresas que fazem uso dos benefícios da Lei do Bem. Entre 2006 e 2012, o número de firmas que acessaram o programa de incentivos fiscais cresceu de 130 para 1.042, mas esse número ainda é considerado reduzido se considerado o número total de 6 mil empresas com atividade de P\&D no Brasil (FABIANI ;SBRAGLIA, 2014, p. 56).

Os dados do Ministério de Ciência e Tecnologia e da Receita 
Federal do Brasil também indicam que o valor dos incentivos fiscais da Lei do Bem ainda são relativamente baixos, se consideradas outras renúncias tributárias, como as incorridas pela Lei da Informática, conforme a tabela seguinte. Em 2014, estima-se que os incentivos da Lei do Bem tenham somado a cifra de R \$ 1,7 bilhão, ante um volume total de $\mathrm{R} \$ 6,9$ bilhões em renúncias de receita relacionadas às leis de incentivo à pesquisa, desenvolvimento e capacitação tecnológica.

Tabela 1 - Valor da renúncia fiscal do governo federal segundo as leis de incentivo à pesquisa, desenvolvimento e capacitação tecnológica em $R \$, 1990-2014$

\begin{tabular}{|c|c|c|c|c|c|c|c|}
\hline \multirow[b]{2}{*}{ Anos } & \multicolumn{6}{|c|}{ Leis } & \multirow[b]{2}{*}{ Total } \\
\hline & $\begin{array}{c}\text { Importação } \\
\text { de } \\
\text { equipamento } \\
\text { s para } \\
\text { pesquisa } \\
\text { pelo CNPq } \\
(8.010 / 90) \\
\end{array}$ & $\begin{array}{l}\text { Isenção ou } \\
\text { redução de } \\
\text { impostos de } \\
\text { importação } \\
(8.032 / 90)\end{array}$ & $\begin{array}{c}\text { Lei de } \\
\text { informática } \\
(8.248 / 91 \mathrm{e} \\
10.176 / 01)^{(1)}\end{array}$ & $\begin{array}{c}\text { Capacitação } \\
\text { tecnológica } \\
\text { da ind. e da } \\
\text { agropecuária } \\
(8.661 / 93 \text { e } \\
9.532 / 97)\end{array}$ & $\begin{array}{c}\text { Lei de } \\
\text { informática } \\
\text { Zona Franca } \\
(8.387 / 91)\end{array}$ & $\begin{array}{c}\text { Lei do Bem } \\
(11.196 / 05)\end{array}$ & \\
\hline 1990 & 0,5 & 0,2 & - & - & - & - & 0,6 \\
\hline 1991 & 5,2 & 0,5 & - & - & - & - & 5,7 \\
\hline 1992 & 44,0 & 4,4 & - & - & - & - & 48,3 \\
\hline 1993 & $1.231,0$ & 197,0 & $5.838,0$ & - & - & - & $7.266,0$ \\
\hline 1994 & $38.530,0$ & $3.306,0$ & $181.286,0$ & 906,0 & - & - & $224.028,0$ \\
\hline 1995 & $59.179,0$ & $9.220,0$ & $255.801,0$ & $9.686,0$ & - & - & $333.886,0$ \\
\hline 1996 & $57.680,0$ & $8.060,0$ & $405.604,0$ & $11.487,0$ & $61.827,0$ & - & $544.658,0$ \\
\hline 1997 & $61.330,0$ & $3.410,0$ & $542.605,0$ & $22.840,0$ & $95.490,0$ & - & $725.675,0$ \\
\hline 1998 & $62.071,0$ & $4.301,0$ & $750.266,0$ & $41.906,0$ & $94.613,0$ & - & $953.157,0$ \\
\hline 1999 & $78.956,0$ & $4.400,0$ & $1.054 .609,0$ & $33.700,0$ & $381.413,0$ & - & $1.553 .078,0$ \\
\hline 2000 & $60.323,3$ & $10.521,6$ & $1.203 .659,6$ & $22.288,7$ & $13.374,1$ & - & $1.310 .167,3$ \\
\hline 2001 & $118.417,8$ & $6.342,3$ & - & $22.446,8$ & $62.400,9$ & - & $209.607,8$ \\
\hline 2002 & $111.861,6$ & $6.516,7$ & $732.900,0$ & $15.220,5$ & $77.630,9$ & - & $944.129,7$ \\
\hline 2003 & $152.011,2$ & $8.201,4$ & $961.665,5$ & $19.668,1$ & $98.126,6$ & - & $1.239 .672,8$ \\
\hline 2004 & $155.944,3$ & $11.427,7$ & $934.631,6$ & $37.120,4$ & $89.494,3$ & - & $1.228 .618,4$ \\
\hline 2005 & $182.611,3$ & $9.782,0$ & $1.300 .836,7$ & $35.314,6$ & $101.804,7$ & - & $1.630 .349,3$ \\
\hline 2006 & $183.435,4$ & $3.801,7$ & $2.038 .482,3$ & $102.834,2$ & $106.542,8$ & $227.859,4$ & $2.662 .955,7$ \\
\hline 2007 & $217.295,3$ & $5.727,5$ & $2.755 .400,2$ & $2.415,9$ & $81.611,2$ & $868.455,2$ & $3.930 .905,3$ \\
\hline 2008 & $385.516,0$ & $5.077,0$ & $3.261 .370,7$ & $1.312,8$ & $128.521,3$ & $1.582 .712,9$ & $5.364 .510,8$ \\
\hline 2009 & $395.952,1$ & $2.077,7$ & $3.103 .252,0$ & 201,4 & $99.680,1$ & $1.382 .758,0$ & $4.983 .921,2$ \\
\hline 2010 & $390.286,5$ & $1.174,4$ & $3.570 .760,0$ & - & $120.654,0$ & $1.727 .138,8$ & $5.810 .013,7$ \\
\hline 2011 & $341.906,2$ & $2.008,7$ & $3.771 .520,0$ & - & $143.421,7$ & $1.409 .983,9$ & $5.668 .840,3$ \\
\hline 2012 & $284.810,4$ & $2.252,9$ & $4.482 .200,0$ & - & $176.942,7$ & $1.476 .804,1$ & $6.423 .010,0$ \\
\hline $2013^{(2)}$ & $333.291,8$ & $2.636,4$ & $4.844 .115,9$ & - & $207.062,5$ & $1.604 .251,7$ & $6.991 .358,2$ \\
\hline $2014^{(2)}$ & $353.582,6$ & $2.796,9$ & $4.580 .409,4$ & - & $219.668,4$ & $1.788 .163,5$ & $6.944 .620,0$ \\
\hline
\end{tabular}

O resultado disso é que o total dispendido pelo país em pesquisa 
e desenvolvimento tem crescido, mas a um ritmo ainda baixo, como pode-se observar pela tabela 2 , que consolida os gastos em P\&D dos governos federal, estaduais e também das empresas privadas e estatais. Como se vê, o dispêndio total cresceu de 1,04\% do PIB em 2000 para cerca de 1,24\% do PIB em 2013, após uma década e meia de práticas de políticas públicas e incentivo à inovação. $\mathrm{O}$ que mais chama a atenção é que, na esfera das empresas, o dispêndio em P\&D permanece estagnado em todo o período em torno de $0,5 \%$ do PIB, tendo atingido um pico em 2010 , correspondente a $0,57 \%$ do PIB, o que revela como o ambiente de incerteza econômica dos últimos anos é inibidor desse tipo de investimento, de alto risco.

Tabela 2 - Dispêndio nacional em pesquisa e desenvolvimento (P\&D) por setores, em proporção do PIB, 2000-2013:

\begin{tabular}{|c|c|c|c|c|c|c|c|c|c|c|c|c|c|c|}
\hline Esfera & 2000 & 2001 & 2002 & 2003 & 2004 & 2005 & 2006 & 2007 & 2008 & 2009 & 2010 & 2011 & 2012 & 2013 \\
\hline Dispêndios públicos & 0,54 & 0,57 & 0,52 & 0,51 & 0,48 & 0,48 & 0,49 & 0,56 & 0,57 & 0,59 & 0,59 & 0,60 & 0,63 & 0,71 \\
\hline Dispêndios federais & 0,33 & 0,35 & 0,32 & 0,34 & 0,33 & 0,33 & 0,35 & 0,38 & 0,39 & 0,40 & 0,41 & 0,41 & 0,42 & 0,50 \\
\hline Orçamento executado & 0,21 & 0,23 & 0,20 & 0,21 & 0,20 & 0,21 & 0,21 & 0,22 & 0,23 & 0,25 & 0,26 & 0,24 & 0,25 & 0,31 \\
\hline Pós-graduação & 0,13 & 0,12 & 0,12 & 0,13 & 0,13 & 0,12 & 0,14 & 0,16 & 0,16 & 0,15 & 0,16 & 0,16 & 0,17 & 0,19 \\
\hline Dispêndios estaduais & 0,21 & 0,22 & 0,20 & 0,18 & 0,15 & 0,15 & 0,14 & 0,17 & 0,18 & 0,18 & 0,18 & 0,20 & 0,21 & 0,21 \\
\hline Orçamento executado & 0,08 & 0,09 & 0,06 & 0,05 & 0,05 & 0,06 & 0,06 & 0,06 & 0,06 & 0,07 & 0,06 & 0,06 & 0,07 & 0,06 \\
\hline Pós-graduação & 0,13 & 0,13 & 0,13 & 0,12 & 0,09 & 0,09 & 0,08 & 0,11 & 0,12 & 0,11 & 0,12 & 0,13 & 0,14 & 0,15 \\
\hline Dispêndios empresariais & 0,50 & 0,50 & 0,49 & 0,49 & 0,49 & 0,52 & 0,49 & 0,52 & 0,56 & 0,53 & 0,57 & 0,54 & 0,52 & 0,52 \\
\hline $\begin{array}{l}\text { Empresas privadas } \mathrm{e} \\
\text { estatais }\end{array}$ & 0,49 & 0,48 & 0,47 & 0,47 & 0,47 & 0,51 & 0,47 & 0,50 & 0,54 & 0,51 & 0,55 & 0,52 & 0,50 & 0,50 \\
\hline Pós-graduaçāo & 0,01 & 0,01 & 0,02 & 0,02 & 0,02 & 0,02 & 0,02 & 0,02 & 0,02 & 0,02 & 0,02 & 0,02 & 0,02 & 0,02 \\
\hline Total & 1,04 & 1,06 & 1,01 & 1,00 & 0,96 & 1,00 & 0,99 & 1,08 & 1,13 & 1,12 & 1,16 & 1,14 & 1,15 & 1,24 \\
\hline
\end{tabular}

Dessa forma, a maior parte da expansão do gasto em pesquisa e inovação se dá na esfera das administrações públicas, tanto federal quanto estadual, devendo-se considerar, ainda, que também são os governos que incentivam o setor privado por meio dos mencionados incentivos fiscais. Tal situação sugere a necessidade de buscar outros mecanismos de incentivo à inovação, além do aprimoramento dos mecanismos tributários e da segurança jurídica em torno dos mesmos.

A este respeito, é importante citar a avaliação de Caroline 
Memória (2013, p. 69), segundo a qual o marco regulatório da Lei do Bem não traria conceitos tão claros a ponto de permitir aos empresários saber com elevado grau de certeza quais projetos de inovação tecnológica e quais dos seus respectivos gastos são enquadráveis na legislação. A Instrução Normativa $\mathrm{n}^{\circ}$ 1.187, de 29 de agosto de 2011, na qual a Receita Federal do Brasil normatiza o que deve ser considerado ou não dispêndio para fins de concessão dos incentivos à inovação tecnológica, parece não ter solucionado as inúmeras dúvidas do empresariado, conforme a autora.

Além disso, a referida autora considera os incentivos fiscais pouco abrangentes, por só contemplarem os gastos destinados à pesquisa, desenvolvimento e inovação (fase de maior incerteza e risco para o empresário) e não alcançarem os investimentos em modernização do pátio industrial. Por fim, avalia que alguns benefícios, na realidade, representam apenas um diferimento (postergação) dos tributos a pagar, tais como o da depreciação e amortização aceleradas integrais, o que muitas empresas acabam não vendo como vantagem suficiente para aderir ao programa.

Outra questão a destacar é a necessidade de dar maior transparência às políticas de incentivo a $\mathrm{P} \& \mathrm{D}$ e atingir as micro e pequenas empresas, onde se dão grande parte das inovações e que, pelos motivos já expostos, estão excluídas da Lei do Bem. Nesse sentido, cabe registrar as iniciativas importantes adotadas por outras esferas de governo que passaram a se preocupar com o tema, no sentido de não só conceder incentivos fiscais, mas também desenvolver programas experimentais que tentam estimular a pesquisa e a inovação.

Este é o caso dos municípios gaúchos de São Leopoldo e Porto Alegre, que reduziram a alíquota de Imposto sobre Serviços de $5 \%$ para $2 \%$ e criaram parques tecnológicos, como o TECNOPUC, o 
Parque Científico e Tecnológico da Pontifícia Universidade Católica do Rio Grande do Sul- RS. No caso de Porto Alegre, a lei complementar 721/2013 prevê não só a redução de ISS, como a possibilidade de isenção total ou parcial do IPTU e de ITBI, entre outros benefícios e tratamentos prioritários às instituições e empresas aderentes.

Em termos mais gerias, contudo, o que se observa é que os incrementos em termos de gastos públicos em pesquisa e incentivos no Brasil ainda são tímidos e liderados pelo governo federal. Da mesma forma, as empresas ainda investem de forma tímida em $P \& D$, o que pode ser explicado, talvez, pelo risco que o negócio representa, pela cultura conservadora, pela burocracia interna e pela centralização de decisões ainda verificada em muitas empresas.

O incremento do investimento privado em inovação demandaria a constante avaliação da efetividade e das necessidades de aperfeiçoamento dos mecanismos de estímulo a esse tipo de investimento no país (MEMÓRIA, 2014, p.69). Da mesma forma, o risco representado pelos investimentos em P\&D, e a atual crise econômica vivenciada pelo Brasil também podem representar razões que agravam a dificuldade de tomada de decisão pelas empresas de realizar este tipo de investimento.

Já em relação à utilização dos incentivos fiscais proporcionados pela Lei do Bem, verificou-se um incremento considerável no número de empresas que se valem desses benefícios, mas o potencial de expansão na utilização dos mesmos é ainda muito expressivo.

\section{CONSIDERAÇÕES FINAIS}

Este artigo estudou o desenvolvimento da extrafiscalidade 
no campo do Direito e da Economia à luz das grandes mudanças de paradigma ocorridas no âmbito do pensamento filosófico, jurídico e econômico ao longo dos últimos séculos. Pretendeu-se demonstrar, ainda, como no caso específico da extrafiscalidade aplicada aos incentivos à inovação, há uma justificação por diferentes teorias econômicas, do keynesianismo ao neoclassicismo, passando pelo schumpeterianismo.

Além disso, seria possível afirmar que, da análise conjugada dos dispositivos contidos nos artigos 170, VI, 174, 218 e 219 da Constituição Federal, as políticas públicas implementadas no âmbito do estado Social e Democrático de Direito instituído em nosso país através da atual Constituição devem necessariamente considerar como prioridades, em termos extrafiscais, a questão do incentivo ao desenvolvimento tecnológico e à inovação, como formas de incentivo ao desenvolvimento econômico.

Embora amplamente respaldados em termos legais, os incentivos fiscais à inovação apresentam resultados bastante tímidos no Brasil e os principais investimentos ainda são feitos pelo governo federal, como indicam as estatísticas relativas aos gastos de P\&D no Brasil e ao acesso aos benefícios da Lei do Bem. Os resultados ainda tímidos desses programas podem ser explicados por diversos fatores, sendo possível elencar, dentre os principais, o risco que o negócio representa, a cultura conservadora ainda existente em muitas empresas, a burocracia interna e a centralização de decisões ainda verificada em muitas empresas.

Além disso, é possível frisar a necessidade de que se dê maior transparência às políticas de incentivo a $\mathrm{P} \& \mathrm{D}$, além de estabelecer fórmulas para que estas possam atingir as micro e pequenas empresas, onde se dão grande parte das inovações e que estão excluídas dos benefícios da Lei do Bem, pois não apuram seus lucros através da 
sistemática do lucro real.

Nesse contexto, cabe registrar as iniciativas importantes adotadas por outros entes federativos, além do governo federal que passaram a se preocupar com o tema, no sentido de não só conceder incentivos fiscais, mas também desenvolver programas experimentais que tentam estimular a pesquisa e a inovação.

Um bom exemplo dessas iniciativas foi a edição da Lei Complementar $n^{\circ} 721 / 2013$, de Porto Alegre, que estabelece medidas de incentivo e apoio à inovação e à pesquisa cientifica e tecnológica no ambiente empresarial, acadêmico e social no Município de Porto Alegre e prevê não só a redução de ISS, como a possibilidade de isenção total ou parcial do IPTU e de ITBI, entre outros benefícios e tratamentos prioritários às instituições e empresas aderentes. Além disso, a referida lei incentiva em âmbito local a criação de condomínios empresariais, parques científicos e tecnológicos e de incubadoras empresariais, o que já vêm produzindo resultados consideráveis, a exemplo dos resultados já consolidados e do impacto positivo na comunidade social e científica gerados pela implementação do Parque Científico e Tecnológico da Pontifícia Universidade Católica do Rio Grande do Sul-RS- TECNOPUC.

\section{REFERÊNCIAS}

ATALIBA, Geraldo. Sistema constitucional tributário brasileiro. São Paulo: Revista dos Tribunais, 1966.

ARAÚJO, Bruno César. Incentivos fiscais à pesquisa e desenvolvimento e custos de inovação no Brasil. Radar: Tecnologia, Produção e Comércio Exterior, Brasília, n. 9. Brasília: IPEA, 2010. Disponível em: http:// www.ipea.gov.br/portal/images/stories/PDFs/100826_radar09.pdf. 
Acesso em 03 ago. 2015.

BALEEIRO, Aliomar. Limitações constitucionais ao poder de tributar. Rio de Janeiro: Forense, 2006.

BARBOSA, Hermano Antonio do Cabo Notaroberto. Regulação econômica e tributação: o papel dos incentivos fiscais. Direito Tributário e Políticas Públicas. São Paulo: MP Editora, 2008.

BRASIL. Constituição da República Federativa do Brasil. Brasília, DF., 1988. Disponível em: < http://www.planalto.gov.br/ccivil_03/ constituicao/constituicaocompilado.htm>. Acesso em: 07 jul. 2015.

BRASIL. Ministério de Ciência e Tecnologia. Indicadores. Disponível em: http://www.mct.gov.br/index.php/content/view/740.html, acesso em 03/08/2015.

BRESSER PEREIRA, Luiz Carlos. Da macroeconomia clássica à keynesiana. Versão corrigida em 1974 de apostila publicada originalmente em 1968. EC-MACRO-L-1968 (E-73). São Paulo, abril de 1968. Revisado em maio de 1976. Disponível em: http://www. bresserpereira.org.br/papers Acesso em 02/11/2015.

CALIENDO, Paulo. Direito tributário: três modos de pensar a tributação. Porto Alegre: Livraria do Advogado, 2009,a.

CALIENDO, Paulo. Direito tributário e análise econômica do Direito, uma visão crítica. Elsevier: Rio de Janeiro, 2009,b. 
CALIENDO, Paulo. Limitações constitucionais ao poder det com finalidade extrafiscal. Revista do Programa de Pós-Graduação em Direito da UFC, Fortaleza, n. 2, p.171-205, jul/dez 2013.

CALIENDO, Paulo. Tributação da Inovação: observações introdutórias direitos fundamentais, direito privado e inovação. In: Direitos fundamentais: direito privado e inovação. Porto Alegre: EdiPUCRS, 2012, p. 147-173.

CALOZAIO, Aziz Eduardo. Política fiscal de incentivo à inovação no Brasil: análise do sesempenho inovativo das empresas que usufruíram benefícios da Lei 11.196/05 (Lei do Bem). Porto Alegre, 2011. Disponível em: <http://www.lume.ufrgs.br/bitstream/ handle/10183/35595/000783678.pdf? sequence $=1>$. Acesso em: 30 out. 2015.

CARVALHO, Paulo de Barros. Curso de direito tributário. 18. ed. São Paulo: Saraiva, 2007.

CORREIA NETO, Celso de Barros Correia. O Avesso do tributo. São Paulo: Almedina, 2014.

FABIANI, Sidirley; SBRAGLIA, Roberto. Tax incentives for technological business innovation in Brazil: the use of the good law. Journal of Technology, Management \& Innovation, v.9, n.4, p. 53-63, nov., 2014. Disponível em: http://www.jotmi.org/index.php/GT/article/ view/1630>. Acesso em 30/10/2015.

FERRARI FILHO, Fernando. Os “keynesianos” neoclássicos e os póskeynesianos. Ensaios da FEE, Porto Alegre, v. 12, n. 2, p. 340-348, 1991. Disponível em: <http://revistas.fee.tche.br/index.php/ensaios/ 
article/viewFile/1452/1816>. Acesso em 02/11/2015.

HADDAD, Evelyn Witt. Inovação tecnológica em Schumpeter e na ótica neo-schumpeteriana. 2010. 76 f. Trabalho de Conclusão de Curso (Graduação) - Faculdade de Ciências Econômicas, Universidade Federal do Rio Grande do Sul, Porto Alegre, 2010. Disponível em: < http://www. lume.ufrgs.br/handle/10183/25385 >. Acesso em: 30 out. 2015.

JARDIM, Eduardo Ferreira; LICHANDLL, Guilherme; GALA, Paulo. Microfundamentos da macroeconomia: notas críticas. Revista de Estudos Econômicos,São Paulo, v. 39, n.4, out./dez, 2009. Disponível em: <http://dx.doi.org/10.1590/S0101-41612009000400006>. Acesso em: 02 nov. 2015.

KEYNES, Jhon Mayard. The general theory of employment, interest and money. New York: [s.n.], 1936.

MANKIW, Gregory. Introdução à economia. 3.ed. São Paulo: Cengave Learning, 2009.

MEMÓRIA, Caroline Viriato. Poucas empresas usam incentivos fiscais à inovação? Jornal Valor Econômico, São Paulo, 22 abr. 2013. Disponível em : <http://www.valor.com.br/imprimir/noticia/3094898/wrap-xhr>. Acesso em: 02 nov. 2015.

MEMÓRIA, Caroline Virato. Incentivos para a inovação tecnológica: um estudo da política pública de renúncia fiscal no Brasil. Brasília, 2014. Disponível em: <http://repositorio.unb.br/ bitstream/10482/17657/1/2014_CarolineViriatoMemoria.pdf>. Acesso em: 30 out. 2015. 
NABAIS, José Casalta. Direito fiscal. Coimbra: Almedina, 2003.

SARLET, Ingo. Os direitos fundamentais sociais na Constituição de 1988. Revista Diálogo Jurídico, Salvador, v. 1, n. 1, abr., 2001.

SCHILling, Voltaire. Capitalismo e teorias da crise (parte II), 2008. Disponível em: <http://educaterra.terra.com.br/voltaire/ cultura/2008/10/15/001.htm>. Acesso em: 15 out. 2015.

SCHILLING, Voltaire. História: cultura e pensamento, [1988].História por Voltaire Schilling. Disponível em: $<$ http://educaterra.terra.com.br/ voltaire/cultura/2008/10/15/001.htm>. Acesso em: 05 nov. 2015.

SCHUMPETER, Joseph A. Business cycles: a theoretical, historical and statistical analysis of the capitalist process. McGraw-Hill Book Company, 1939.

SCHUMPETER, Joseph A. Capitalismo, socialismo e democracia. Rio de Janeiro: Fundo de Cultura, 1961. Disponível em: $<$ http://uenf.br/cch/ lesce/files/2013/08/Texto-3.pdf>. Acesso em: 31 out. 2015.

SMITH, Adam. Riqueza das nações. 1. ed. São Paulo: Folha de S.Paulo, 2010.

SUSTEIN, Cass. (Más) Simple, el futuro del gobierno. Madrid: Marcial Pons, 2014.

VERBEN, Thorstein. The preconceptions of economic science-III. The Quarterly Journal of Economics. v. 14, n. 2, fev., p. 240-269, 1990.

Como citar: LAKS, Larissa Rodrigues. Extrafiscalidade e incentivos à inovação tecnológica. Revista do Direito Público, Londrina, v. 11, 
n. 2, p.230-259, ago. 2016. DOI: 10.5433/1980-511X.2016v11n2p230. ISSN: $1980-511 \mathrm{X}$.

Submetido em 09/02/2016

Aprovado em 30/05/2016 